\title{
Grítica
}

\section{Por uma Antropologia Histórica - resenha de "Os caminhos da pesquisa antropológica: Homenagem a Beatriz Góis Danta"s, de Eufrázia Menezes e Sílvia Góis Dantas}

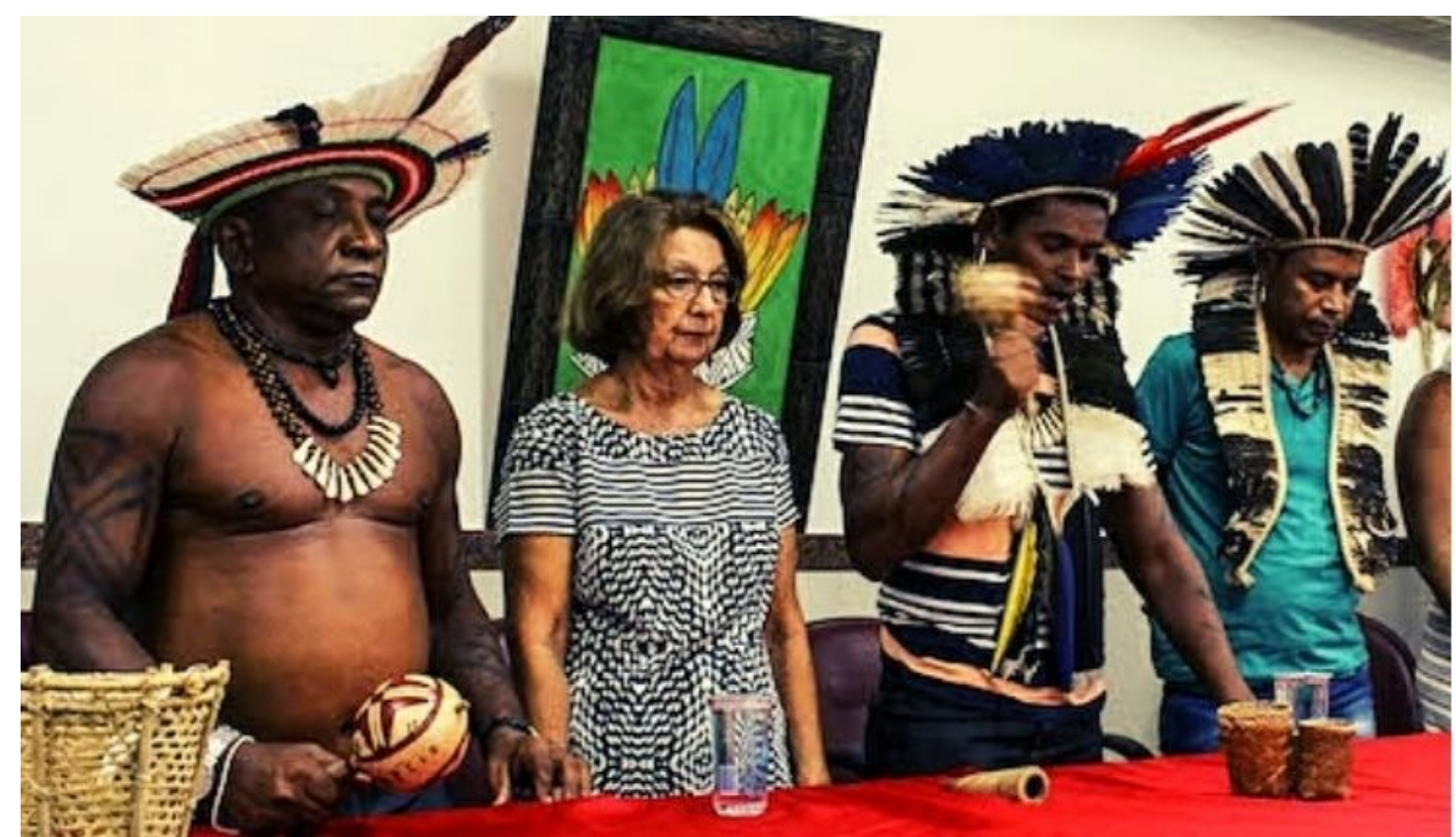

Beatriz Góis Dantas com o Cacique Lucimário Ba Xocó à sua esquerda | Foto: Carolina Timoteo/ADUFS (2019)

Os caminhos da pesquisa antropológica: homenagem a Beatriz Góis Dantas, foi lançado há dois meses, em clima fraternal, em live no Youtube (Link). Presentes ao ato, além de Beatriz Dantas, estavam as organizadoras da obra Sílvia Dantas e Eufrázia Cristina Menezes, respectivamente, filha e ex-aluna da antropóloga e historiadora Beatriz Góis Dantas. A própria homenageada, na ocasião, traçou uma "cartografia afetiva e intelectual" da inserção de vários antropólogos e historiadores em sua vida de pesquisadora, em quase seis décadas de atividades. 


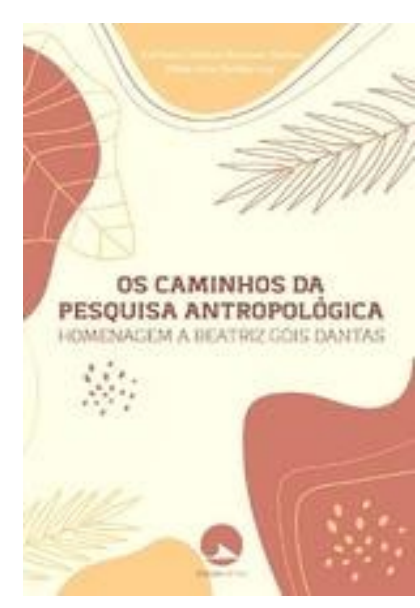

A cartografia se expressa no próprio livro que, em suas três partes (trajetória acadêmica, experiência na Antropologia e testemunhos de colegas), reúne 14 autores com atuação acadêmica local e transnacional. Há cenas familiares, relatos autobiográficos, anedóticos de trabalho, periodização clássica da carreira, reconhecimentos e agradecimentos por auxílios pessoais e até um poema de Maria Lúcia Dal Farra, dedicado à "Missionária da memória". Há descrição, crítica e reconhecimento da contribuição de Beatriz Dantas nos domínios da Arquivística, Museologia, Antropologia e (apesar do título do livro) História.

Em meio a esses estudos de diferentes áreas do conhecimento, realizados pela professora, e comentados na obra em questão, que desafiam generalistas e especialistas, gostaria de recortar o diálogo (nada consensual) entre essas duas últimas disciplinas. Se antropólogos, como F. Boas, introduziram a história em seu fazer antropológico, a escola inglesa de Radcliffe Brown e Bronislaw Malinowski adotou um modelo empiricista e a-histórico na sua escrita. No caso dos textos de Claude Lévi-Strauss, sobre História e Etnologia (1949 e 1983), identificamos certa ambiguidade, já que, no primeiro, que pode ser considerado uma introdução da Antropologia Estrutural, em sua busca de leis universais, afastava-se da história, sendo que, no último ensaio, houve certa aproximação com a história, quando afirmou que a etnologia deveria trabalhar sociedades complexas, compreendendo as rupturas históricas e as mudanças que antes pretendia ignorar (Schwarcz, 2000, p.25).

Muita tinta foi gasta nesse debate, com aproximações e afastamentos entre antropólogos e historiadores, mas, atualmente, penso haver certo consenso de que "o encontro é sempre mais rico do que o isolamento" (Agostini, 2000, p.34). Exemplar nessa direção é a contribuição do trabalho da antropóloga Beatriz Góis Dantas, tão bem sintetizada nesse livro, em homenagem aos seus oitenta anos.

Por certo, o diálogo transdisciplinar entre História e Antropologia serve de projeto intelectual para se evitar o anacronismo e o etnocentrismo, especialmente ao lidar com as culturas subalternas em suas mais variadas manifestações. Nessa interface, as pesquisas de Dantas se relacionam "aos problemas da preservação do patrimônio histórico e artístico; construção/preservação da memória de grupos e instituições sergipanas; levantamento e organização de fontes documentais" (p.92). Destacamos, nessa convergência de interesses etno-históricos, a experiência de reorganização do Arquivo Pública do Estado de Sergipe (1970) e o Levantamento de Fontes Primárias da História de Sergipe (1972), capitaneado pelo professor José Silvério Leite Fontes, do Departamento de Filosofia e História.

Parte significativas dessas temáticas é discutida pela professora Terezinha Oliva, que destaca a contribuição da homenageada na salvaguarda do patrimônio documental. Atuando no "Projeto de Reorganização do Arquivo Público Estadual de Sergipe", na década de 70 do século passado, Beatriz Dantas impulsionou a "fase heurística" da produção historiográfica sergipana, proporcionando aos estudiosos as mínimas condições para atender a pesquisa histórica. (p.155)

Essa experiência lhe deu suporte para colaborar na produção de um dossiê com documentação escrita, fundamental para a luta de reconhecimento dos Índios Xocó, no sertão do São Francisco sergipano, iniciada em 1978. Escrito com Dalmo Dallari, o livro Terra dos Índios Xocó foi publicado pela Comissão Pró-Índio de São Paulo, em 
1980, é exemplar da cuidadosa pesquisa histórica aliada à militância antropológica, no contexto da redemocratização brasileira.

Segundo Manuela Carneiro da Cunha, esse livro, publicado no calor dos acontecimentos, foi pioneiro no campo da antropologia por dar importância aos documentos históricos para a defesa dos direitos territoriais indígenas. Também foi “o germe do projeto que criou em 1985, na Universidade de São Paulo, o Núcleo de História Indígena e do Indigenismo (hoje CEestA), e seu programa de pesquisa ampla de fontes locais, apoiado pela Fapesp" (p.252). De sua participação ativa no projeto resultaram em publicações, como Repertório de documentos para a História Indígena: Arquivo Público do Estado de Sergipe (1993) e Guia Brasileiro de Fontes para a História Indígena e do Indigenismo em Arquivos Brasileiros (1980).

No mesmo diapasão, Dantas escreveu ainda um trabalho considerado clássico da antropologia brasileira, Vovô Nagô, Papai Branco: usos e abusos da África no Brasil (1988). No texto, ela revela as tentativas de legitimação e legalização do candomblé, efetuadas no Nordeste, sobretudo nas décadas de 30 e 40, com o concurso dos intelectuais que, diferentemente do que ocorreu no Sudeste em relação à umbanda, privilegiou a herança cultural africana, sobretudo a "nagô mais pura". Para ela, as categorias "puro" e "misturado" servem para classificar os terreiros de candomblé, articulando-se como esquema de forças simbólicas dos dominantes, em que se explicita de que maneira a herança cultural africana foi transformada em distintivo regional, símbolo da nação e da democracia racial e cultural brasileira. Nesse jogo de negociação, a autora sugere, por outro lado, que esta estratégia é usada também pelos terreiros para sua sobrevivência.

Como bem apontou Peter Fry, Dantas contribuiu, decisivamente, com a ideia de que "a formação do campo religioso afro-brasileiro só poderia ser entendida quando vista no contexto mais abrangente da sociedade brasileira como um todo" (p.248-249).

Essas contribuições colocam, com certeza, a professora Beatriz Góis Dantas entre as principais etno-historiadoras do Nordeste, "seja pelo volume de publicações, pela diversidade dos grupos tribais e temas pesquisados, seja ainda por sua preocupação política engajada da defesa da cidadania dos remanescentes dessa etnia", como declarou Luiz Mott (p.121).

Como recorte, esse breve texto não dá conta da intelectual multifacetada que é Beatriz Góis Dantas, pois em outras áreas, como museologia ou folclore, ela também desempenhou papel de destaque. É a própria Eufrázia Santos quem destaca: no primeiro caso, Dantas se preocupava com a educação patrimonial, e, no segundo, com "o caráter dinâmico, polifônico e relacional da cultura popular" (p.91).

Beatriz Dantas formou gerações de professores e pesquisadores, bem como gestores e técnicos da área cultural. Esse livro é justa homenagem à brilhante carreira de uma profissional dedicada a pesquisa e à docência, exercidas ao longo de décadas nas instituições educacionais e culturais em Sergipe. Nele encontramos aspectos da aventura do trabalho de antropólogo, do diálogo com outras ciências humanas, dos dilemas políticos e, principalmente, da responsabilidade social demonstrada pela pesquisadora com a experiência da cultura e a educação científica dos universitários.

\section{Referências}

AGOSTINI, Ailton José. Jacques Le Goff: por uma nova fronteira entre Antropologia e História. In: SCHWARCZ, Lilia e GOMES, Nilma Lino (org.). Antropologia e História: debate em região de fronteira. Belo Horizonte: Autêntica, 2000. 
SANTOS, Eufrázia Menezes e DANTAS, Sílvia Góis (org.). Os caminhos da pesquisa antropológica: Homenagem a Beatriz Góis Dantas. Aracaju: Criação, 2021.

SCHWARCZ, Lilia. História e Antropologia: embates em região de fronteira. In: SCHWARCZ, Lilia e GOMES, Nilma Lino (org.). Antropologia e História: debate em região de fronteira. Belo Horizonte: Autêntica, 2000.

\section{Sumário de Os caminhos da pesquisa antropológica: homenagem a Beatriz Góis Dantas}

- Parte I. Trajetória acadêmica e a paixão pela Antropologia

- O percurso de Beatriz - Ibarê Dantas

- A Antropologia vibrante de Beatriz Góis Dantas - Maria Laura Viveiros de Castro Cavalcanti

- Beatriz Góis Dantas e a Antropologia em Sergipe: notas preliminares

- Eufrázia Cristina Menezes Santos

- Parte II. Caminhos e desafios da pesquisa antropológica

- Beatriz Góis Dantas: pesquisadora, professora e ativista cultural - Luiz Mott

- Beatriz Góis Dantas: mulher perguntadeira - Osvaldo Meira Trigueiro

- Beatriz Góis Dantas e o patrimônio cultural - Terezinha Alves de Oliva

- Beatriz Góis Dantas, museologia e museu na Universidade Federal de Sergipe - Verônica Maria Menezes Nunes

- Memórias das experiências com os estudos sobre os Povos Indígenas da professora Beatriz Góis Dantas e apontamentos acerca do seu legado para a juventude pesquisadora - Diogo Francisco Cruz Monteiro e Kleber Rodrigues

- A arquitetura viva do mundo: o terreiro como epicentro - Vagner Gonçalves da Silva

- Festa, religião e cidade: experiência e expertise, em homenagem, e com imensa gratidão, à dona Beatriz -Léa Freitas Perez

- $\quad$ Parte III. Depoimentos

- Desvendando Áfricas - Peter Fry

- Para Beatriz - Manuela Carneiro da Cunha

- Carta à amiga Beatriz - Maria Thereza Lemos de Arruda Camargo

- Sobre os autores

- Beatriz Góis Dantas 


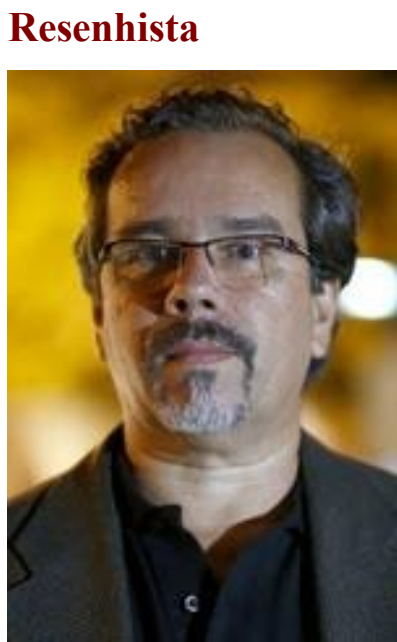

Antônio Fernando de Araújo Sá- Doutor em História pela Universidade de Brasília (UnB), professor do Departamento de História e do Mestrado em História da Universidade Federal de Sergipe e editor da Ponta de Lança - Revista Eletrônica de História, Memória \& Cultura. Publicou, entre outros títulos, Rio Sem História? Leituras sobre o Rio São Francisco (2018) e Entre sertões e representações: ensaios e estudos (2021). E-mail: fernandosa1965@gmail.com.

\section{Para citar esta resenha}

SANTOS, Eufrázia Menezes e DANTAS, Sílvia Góis (org.). Os caminhos da pesquisa antropológica: Homenagem a Beatriz Góis Dantas. Aracaju: Criação, 2021. Resenha de: SÁ, Antônio Fernando de Araújo. Por uma Antropologia Histórica. Crítica Historiográfica. Natal, v.2, n.1, jan./fev. 2022. Disponível em: https://www.criticahistoriografica.com.br/os-caminhos-da-pesquisa-antropologicahomenagem-a-beatriz-gois-dantas-eufrazia-menezes-e-silvia-gois-dantas/

\section{Baixar esta resenha em PDF}

Outras resenhas sobre Os caminhos da pesquisa antropológica: homenagem a Beatriz Góis Dantas

Claudefranklin Monteiro Santos - AJN (2021)

(C) - Os autores que publicam em Crítica Historiográfica concordam com a distribuição, remixagem, adaptação e criação a partir dos seus textos, mesmo para fins comerciais, desde que lhe sejam garantidos os devidos créditos pelas criações originais. (CC BY$\mathrm{SA})$ 